\title{
EFFICACY AND SAFETY EVALUATION OF TWO TYPES OF RECRUITMENT MANEUVER AFTER ONE LUNG VENTILATION IN THORACIC SURGERY
}

\author{
${ }_{\text {A. Gritsan }}^{1}$, D. Mitsukov², V. Ishutin ${ }^{2}$, V. Novokreshchennykh², N. Khodyunya ${ }^{2}$, L. Nosova ${ }^{3}$ \\ ${ }^{1}$ Krasnoyarsk Regional Clinical Hospital, Krasnoyarsk State Medical University, ${ }^{2}$ Krasnoyarsk Regional Clinical Hospital, \\ ${ }^{3}$ Krasnoyarsk State Medical University, Krasnoyarsk, Russia
}

Thoracic surgery often requires one lung ventilation (OLV) To continue the traditional double lung ventilation (DLV), the recruitment maneuver (RM) is one of the methods for restoring gas exchange in the collapsed lung.
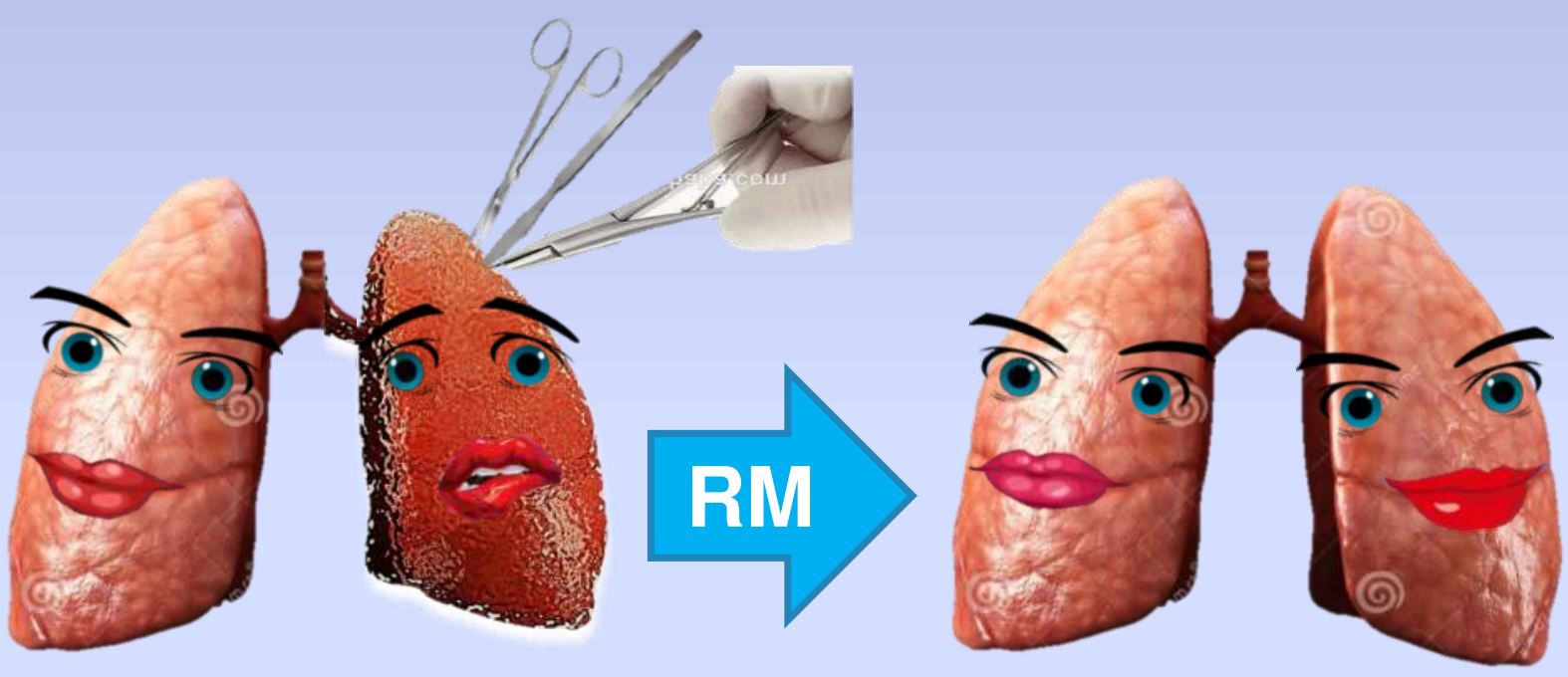

Objective: This paper aims to assess the effect of two different RM methods on oxygenation parameters, respiratory mechanics and hemodynamics in patients operated with OLV.

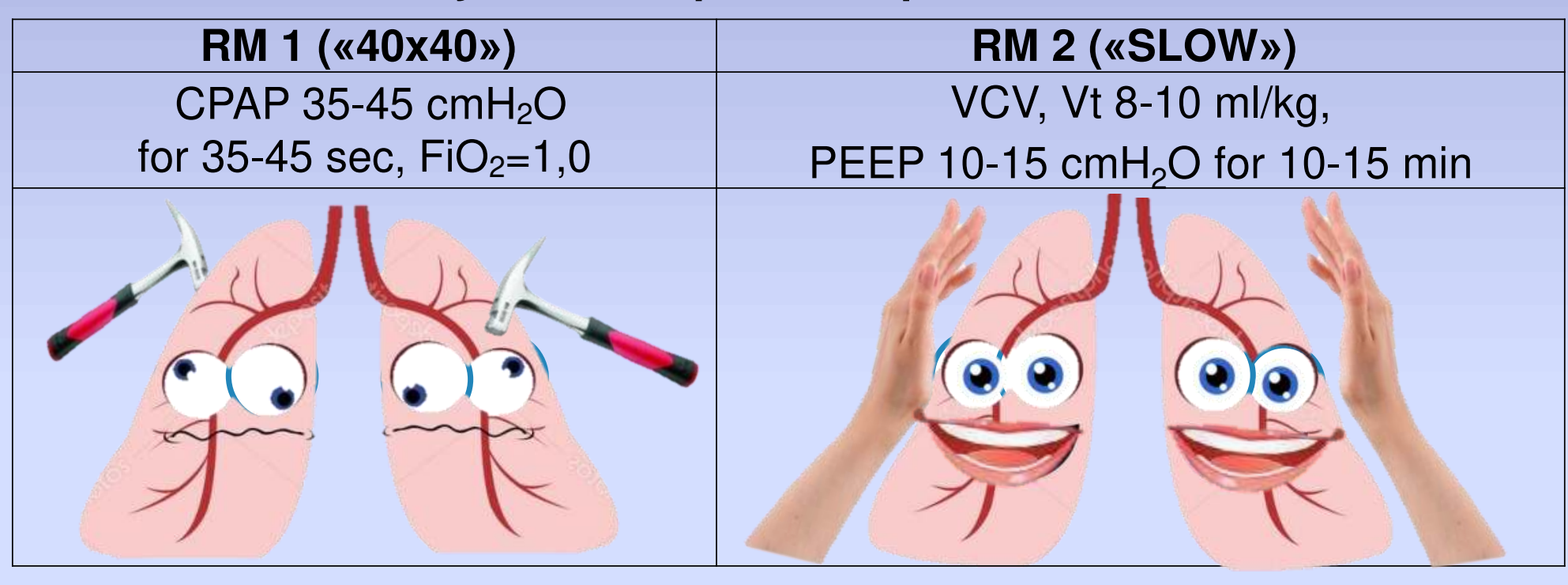

Materials and methods: The study included two groups of 20 patients in each, who underwent thoracoscopy and OLV. The RM method «40x40» was applied for the patients of the first group (RM 1), whereas a «slow» RM was applied for the patients of the second group (RM 2). The efficacy of the procedure was assessed visually by the state of the pulmonary parenchyma, as well as the oxygenation indices $\left(\mathrm{PaO}_{2}\right.$, $\mathrm{ScvO}_{2}$, Qs/Qt), respiratory mechanics (PIP, Ppl, Pdr, Cdyn, Raw) and hemodynamics (MAP, CVP, HR) before and after its carrying out.

Results and discussion: RM was successfully completed for the patients of both groups and it was confirmed by the expansion of the operated lung, as well as a significant improvement in oxygenation (an increase

in $\mathrm{PaO}_{2}$, and $\mathrm{ScvO}_{2}$, a decrease in Qs/Qt) and

respiratory mechanics (an increase in Cdyn with a simultaneous decrease in Raw). At the same time, there were no significant differences between these indices in patients of the both groups before and after the RM.
The essential difference was revealed in relation to the $\mathrm{RM}$ influence on the pressure in the airways (AW) and hemodynamics (at a similar initial level of the corresponding indices).
Comparative assessment of indices of pressure in AW after RM

Paw, $\mathrm{cmH}_{2} \mathrm{O}$

60

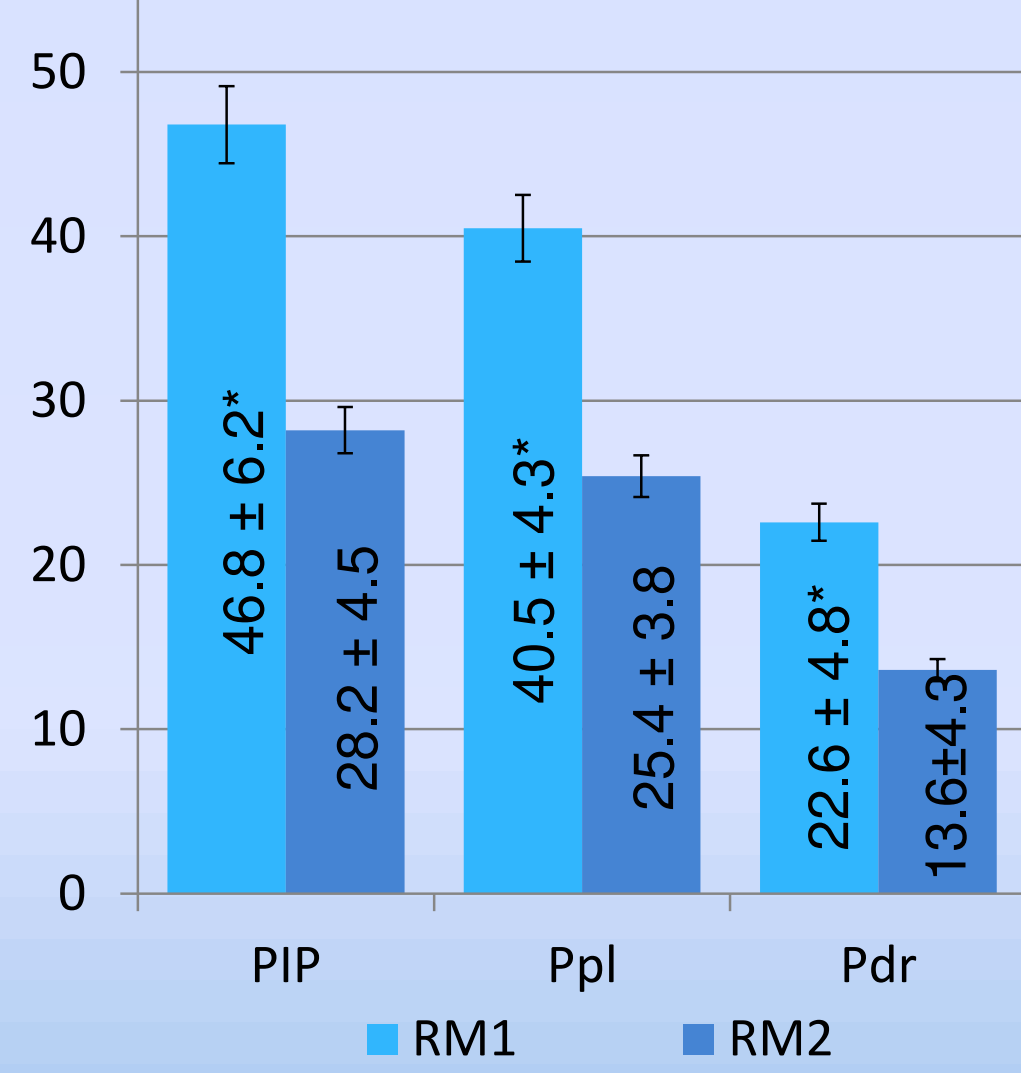

* - the difference between groups is reliable; $p<0.05$

\section{Comparative assessment} of indices of HR after RM

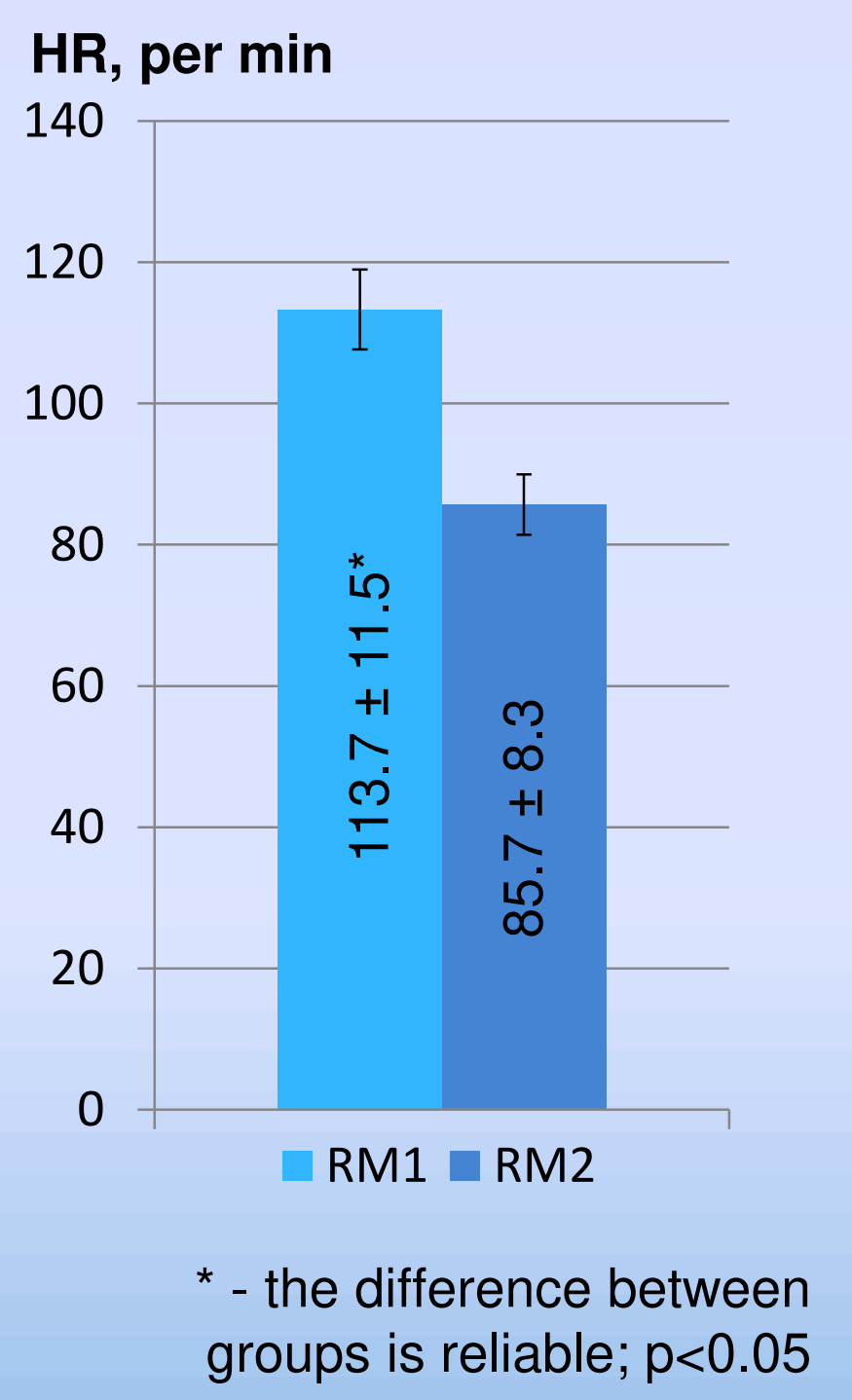

Comparative assessment of Indices of the CVP after RM CVP, $\mathrm{mmH}_{2} \mathrm{O}$

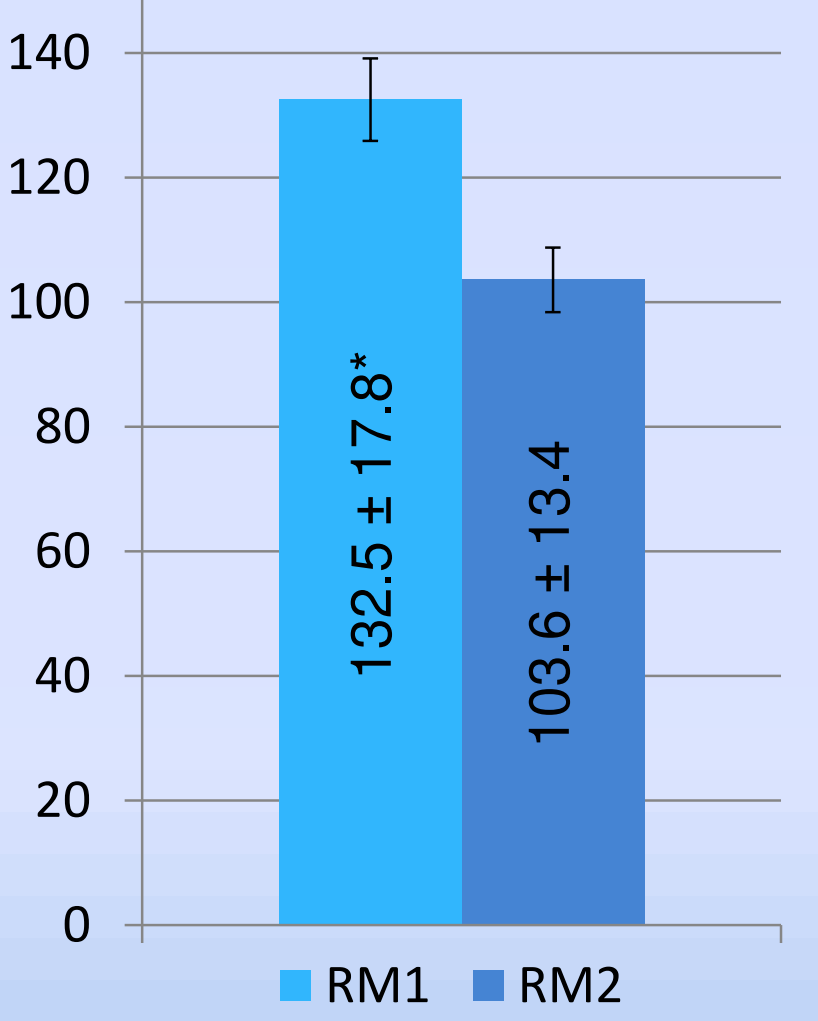

* - the difference between groups is reliable; $p<0.05$
Comparative assessment of indices of MAP after RM

\section{MAP, $\mathrm{mmHg}$ \\ 100}

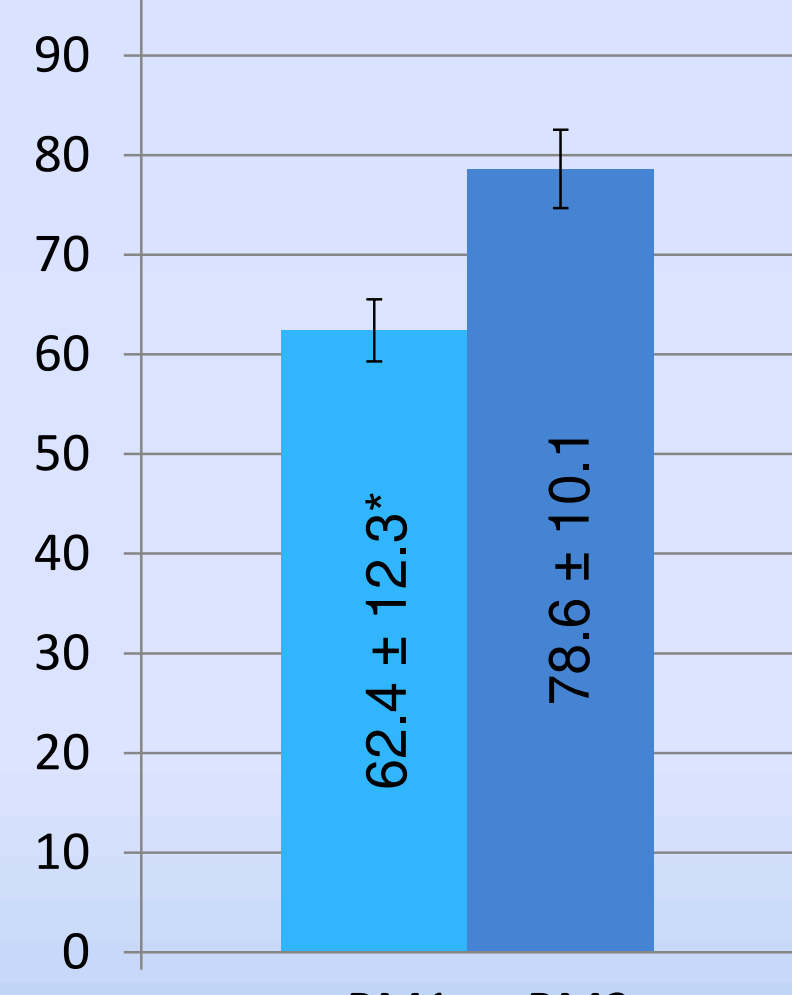

$\square \mathrm{RM} 1 \square \mathrm{RM} 2$

* - the difference between groups is reliable; $p<0.05$

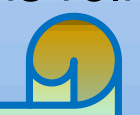

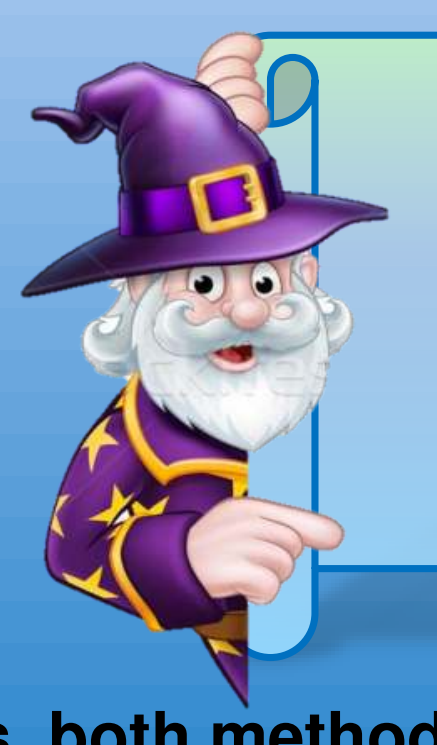

It is obvious that the method «40x40», a faster one and therefore more «aggressive», significantly increases pressure in the AW, which leads to the rise in intrathoracic pressure (ITP) and the CVP, a reduction of venous return with a decrease in cardiac output and the level of MAP. The developing tachycardia is compensatory in nature.

\section{Conclusion:}

Thus, both methods of performing RM demonstrate similar efficacy, improving oxygenation and respiratory mechanics. At the same time, the «40x40» method has a more evident negative effect on hemodynamics and it 